\title{
Poly(ADP-ribose) polymerase inhibition protects neurons and the white matter and regulates the translocation of apoptosis-inducing factor in stroke
}

\author{
KATALIN KOMJÁTI ${ }^{1,2}$, JOHN G. MABLEY ${ }^{1}$, LÁSZLÓ VIRÁG ${ }^{1}$, GARRY J. SOUTHAN ${ }^{1}$, \\ ANDREW L. SALZMAN ${ }^{1}$ and CSABA SZABÓ ${ }^{1,2}$ \\ ${ }^{1}$ Inotek Pharmaceuticals Corporation, Suite 419E, 100 Cummings Center, Beverly, \\ MA 01915, USA; ${ }^{2}$ Institute of Human Physiology and Clinical Experimental Research, \\ Semmelweis University Medical School, Budapest, Hungary
}

Received October 20, 2003; Accepted November 26, 2003

\begin{abstract}
Focal cerebral ischemia activates the nuclear protein poly(ADP-ribose) polymerase (PARP). Apoptosis-inducing factor (AIF) is a flavoprotein that is normally confined to the mitochondria, but translocates to the nucleus, as shown by in vitro models of neuronal injury. Using INO-1001, a novel potent inhibitor of PARP, we determined the role of PARP activation in the process of AIF translocation in a rat model of focal cerebral ischemia. The potency of INO-1001 as a PARP inhibitor and its cytoprotective potential in oxidantchallenged human neuronal SK-N-MC cells was first confirmed in vitro. PARP inhibition markedly reduced infarct size and improved neurological status in both transient and permanent models of MCA occlusion in Sprague-Dawley rats, with a therapeutic window of $6 \mathrm{~h}$ and $2 \mathrm{~h}$ in the transient and permanent ischemia models, respectively. The PARP inhibitor reduced the accumulation of poly(ADP-ribose) in the ischemic/ reperfused hemisphere and reduced the accumulation of APP in the white matter of the affected hemisphere, consistently with protection against neuronal necrosis and axonal damage, respectively. Immunohistochemical analysis showed the appearance of AIF labeling in neuronal nuclei of the border zone ischemic area in the striatum after stroke. Cytoplasmatic (axonal) AIF staining was significantly diminished in the
\end{abstract}

Correspondence to: Dr Csaba Szabó, Inotek Pharmaceuticals Corporation, Suite 419E, 100 Cummings Center, Beverly, MA 01915, USA

E-mail: szabocsaba@aol.com

Abbreviations: AIF, apoptosis-inducing factor; APP, amyloid precursor protein; MCA, middle cerebral artery; MCAO, middle cerebral artery occlusion; NT, nitrotyrosine; PARP, poly(ADP-ribose) polymerase

Key words: stroke, apoptosis, necrosis, ischemia, brain, NMDA, poly(ADP-ribose), nitric oxide, superoxide, peroxynitrite, mitochondria necrotic core of the striatum, while it was somewhat enhanced at the borderline ischemic territories of the white matter. Inhibition of PARP with INO-1001 reshifted the location of the apoptotic marker to the axons in the ipsilateral striatum. Thus, PARP inhibition is neuroprotective and regulates the ischemic nuclear translocation of AIF in stroke.

\section{Introduction}

Focal cerebral ischemia activates the nuclear protein poly(ADP-ribose) polymerase (PARP) by single DNA strand breaks, which leads to energy depletion and cell death and significantly contributes to the pathogenesis of stroke (overviewed in ref. 1).

Apoptosis-inducing factor (AIF) is a flavoprotein that is normally confined to the mitochondrial intermembrane space, yet translocates to the nucleus, as shown in experimental models of neuronal injury in vitro. Deletion or inhibition of PARP protects against ischemic brain injury and prevents AIF translocation in vitro (2).

Here, using INO-1001, a novel potent inhibitor of PARP $(3,4)$, we determined the role of PARP activation in the process of AIF translocation in stroke in vivo.

\section{Materials and methods}

In vitro PARP activity and cytoprotection studies. The potency of the isoindolinone-based novel PARP inhibitor INO-1001 $(3,4)$ was determined in vitro using purified PARP enzyme as previously described using a commercially available PARS inhibition assay kit (Trevigen, Gaithersburg, MD) (3). The potency of INO-1001 was compared with that of PJ34 $(5,6)$, a phenanthridinone-based potent PARP inhibitor, and with 3-aminobenzamide, a prototypical benchmark PARP inhibitor. The assay was carried out in 96-well ELISA plates following manufacturer's instructions. Briefly, wells were coated with $1 \mathrm{mg} / \mathrm{ml}$ histone $(50 \mu \mathrm{l} /$ well $)$ at $4^{\circ} \mathrm{C}$ overnight. Plates were then washed four times with PBS and then blocked by adding $50 \mu \mathrm{l}$ Strep-Diluent (supplied with the kit). After incubation ( $1 \mathrm{~h}$, room temperature) plates were washed four times with PBS. Appropriate dilutions of PARP inhibitors were combined 
with $2 \mathrm{X}$ PARP cocktail $\left(1.95 \mathrm{mM} \mathrm{NAD}{ }^{+}, 50 \mu \mathrm{M}\right.$ biotinylated $\mathrm{NAD}^{+}$in $50 \mathrm{mM}$ Tris $\mathrm{pH} 8.0,25 \mathrm{mM} \mathrm{MgCl}_{2}$ ) and high specific activity PARP enzyme (both supplied with the kit) in a volume of $50 \mu \mathrm{l}$. Reaction was allowed to proceed for $30 \mathrm{~min}$ at room temperature. After four washes in PBS, incorporated biotin was detected by peroxidase-conjugated streptavidin (1:500 dilution) and TACS Sapphire substrate.

Subsequent studies utilized a standard cytotoxicity assay in thymocytes from C57/BL6 mice. Animals received food and water ad libitum, and lighting was maintained on a 12-h cycle. Thymi from 3-4 weeks old male mice were aseptically removed and placed into ice cold RPMI media supplemented with $10 \% \mathrm{v} / \mathrm{v}$ fetal calf serum, $10 \mathrm{mM}$ glutamine, $10 \mathrm{mM}$ HEPES, $100 \mathrm{U} / \mathrm{ml}$ penicillin, $100 \mu \mathrm{g} / \mathrm{ml}$ streptomycin. Single cell suspensions were prepared by sieving the organs through a stainless wire mesh. Cells isolated this way were routinely $95 \%$ viable, as assessed by Trypan blue exclusion assay. Thymocytes $\left(10^{6}\right.$ cells in $0.5 \mathrm{ml}$ medium $)$ were seeded in 24 -well plates. Cells were pretreated with INO-1001, PJ34 or 3-AB for $20 \mathrm{~min}$. Peroxynitrite was diluted in phosphate buffered saline (PBS) (pH 11.0) and added to the cells in a bolus of $50 \mu \mathrm{l}$. Cells were then incubated for $4 \mathrm{~h}$ for measurement of cell necrosis by the propidium iodide staining method. Decomposed peroxynitrite (incubated for $30 \mathrm{~min}$ at $\mathrm{pH}$ 7.0) served as control, and failed to influence the parameter studied. Thymocytes were stained with $5 \mu \mathrm{g} / \mathrm{ml}$ propidium iodide for $15 \mathrm{~min}$ at $37^{\circ} \mathrm{C}$, washed once with PBS and cell necrosis analyzed with a FacsCalibur flow cytometer, as described (5).

In order to compare and confirm the potency and cytoprotective potential of INO-1001 and PJ34 in a human neuronal cell line, we utilized the human neuronally-derived SK-N-MC cell line (obtained from ATCC). Cells were plated at a density of 250,000 cells per well in 12-well plates. Following $24 \mathrm{~h}$ the media was replaced and the cells treated with increasing concentrations of INO-1001 for 15 min prior to the addition of a stimulator of PARP activity, $750 \mu \mathrm{M}$ of either peroxynitrite or hydrogen peroxide, for a further $25 \mathrm{~min}$. For the measurement of PARP activity, the media was removed and replaced with $0.5 \mathrm{ml}$ HEPES $(\mathrm{pH} 7.5)$ containing $0.01 \%$ digitonin and ${ }^{3} \mathrm{H}-\mathrm{NAD}(0.5 \mu \mathrm{Ci} / \mathrm{ml})$ for $20 \mathrm{~min}$. The cells were then scraped from the wells and placed in Eppendorf tubes containing $200 \mu \mathrm{l}$ of ice-cold $50 \%$ TCA (w/v), the tubes were then placed at $4^{\circ} \mathrm{C}$. After $4 \mathrm{~h}$ the tubes were centrifuged at $1,800 \mathrm{~g}$ for $10 \mathrm{~min}$ and the supernatant removed, the pellet was washed twice with $500 \mu$ ice-cold $5 \%$ TCA. The pellet was solubilized in $250 \mu \mathrm{l} \mathrm{NaOH}(0.1 \mathrm{M})$ containing $2 \%$ SDS overnight at $37^{\circ} \mathrm{C}$, the PARS activity was then determined by measuring the radioactivity incorporated using a Wallac scintillation counter. The solubilized protein $(250 \mu \mathrm{l})$ was mixed with $5 \mathrm{ml}$ of scintillant (ScintiSafe Plus, Fisher) before being counted for $10 \mathrm{~min}$. Results are expressed as a percentage of the PARP activity observed in cells not treated with INO1001.

SK-N-MC cell viability was determined by the reduction of yellow MTT into a purple formazan product by mitochondrial dehydrogenases of metabolically active cells as described (5). SK-N-MC cells were treated for $2 \mathrm{~h}$ with either peroxynitrite $(0.5 \mathrm{mM})$ or hydrogen peroxide $(0.2 \mathrm{mM})$ with and without INO-1001. Following this treatment period the media was removed and $200 \mu \mathrm{l}$ MTT $(1 \mathrm{mg} / \mathrm{ml})$ added. After $1 \mathrm{~h}$ the MTT solution was carefully removed and the purple crystals were solubilized in $100 \mu$ of DMSO. The DMSO was transferred to an ELISA plate and absorbance measured at $550 \mathrm{~nm}$ with a $620 \mathrm{~nm}$ reference. The results are expressed as a percentage of the absorbance obtained from untreated control cells.

Focal cerebral ischemia studies. The investigation conformed to the Guide for the Care and Use of Laboratory Animals published by US National Institutes of Health (NIH Publication No. 85-23 revised 1985) and was performed with the approval of the local Institutional Animal Care and Use Committee.

Seventy Sprague-Dawley male adult rats weighing 300$360 \mathrm{~g}$ were used. Thirty-six rats underwent transient middle cerebral artery occlusion (MCAO) lasting $2 \mathrm{~h}$ and then were allowed to survive another $22 \mathrm{~h}$. In 24 rats the MCA was permanently occluded for $24 \mathrm{~h}$ and in 10 rats for 1 week. Animals were spontaneously respirated by room air supplemented with $\mathrm{O}_{2}$. Anesthesia was induced by pentobarbital (65 mg/kg i.p.) and supplementary doses of the anesthetics were added throughout the surgical procedure $(22 \mathrm{mg} / \mathrm{kg}$ i.p.). The core body temperature was monitored and maintained at $37^{\circ} \mathrm{C}$ with a rectal thermometer and a servo-controlled heating pad till the animal fully recovered. Blood gas analysis was carried out from left femoral artery at the beginning and at the end of the surgery (Ciba-Cornig 856 series). Animals with $\mathrm{PaCO}_{2}>45 \mathrm{mmHg}$ and $\mathrm{PaO}_{2}<95 \mathrm{mmHg}$ were excluded from the study.

Focal cerebral ischemia was induced with the intraluminal vascular occlusion technique (7). Animals were placed in supine position and neck incision made just lateral to the trachea allowing exposure of the left common carotid artery (CCA). Connective tissue surrounding CCA, external carotid artery (ECA) and internal carotid artery (ICA) was removed and occipital-, superior thyroid and terminal lingual and maxillary arteries were electro-coagulated. A 6.0 suture was tied around the pterygopalatine artery at the bifurcation between the ICA and the pterygopalatine artery. A microvascular clip was placed on the CCA and ICA and ECA was electro-coagulated distal from the bifurcation of ECA and ICA. A suture then was tied loosely around the stump and a heat blunted 3.0 monofilament was inserted in the ECA and advanced up through the ICA for approximately $22 \mathrm{~mm}$ until resistance was felt to block the origin of the MCA.

In 36 animals the thread was removed after $2 \mathrm{~h}$ of occlusion (transient MCAO); it remained in place in the remaining 34 animals (permanent MCAO). The muscles and skin of the animals were sutured and the animals were given access to water and soft food. At $24 \mathrm{~h}$ from the induction of ischemia the animals were reanesthetized by pentobarbital $(65 \mathrm{mg} / \mathrm{kg}$ i.p.) and the removed brains were either used for infarct size analysis (TTC staining) or immunohistochemical labeling.

Animals were observed from the onset of ischemia in all groups for assessment of neurological deficits. In 10 rats the neurological scores were followed for 1 week after induction of permanent MCAO.

All animals that died prior to designated time $(24 \mathrm{~h})$ were examined to exclude subarachnoid or subdural hemorrhage from the study. 
We used different time course administrations of INO-1001 in a total dose of $3 \mathrm{mg} / \mathrm{kg}$ intraperitoneally (i.p.). During transient MCAO we applied 3 different treatment regimens:

Two-hour protocol: we administered $40 \%$ of the total given dose at $2 \mathrm{~h}$ after the onset of ischemia, then $20 \%$ of the total dose was given at the 6th, at the 12 th and at the 18th hour.

Four-hour protocol: $50 \%$ of the total given dose was administered at $4 \mathrm{~h}$ after the onset of ischemia, then $10 \%$ was given at the $6 \mathrm{th}$, and $20 \%$ of the total dose at the 12 th and at the 18th hour.

Six-hour protocol: $60 \%$ of the total given dose was administered at $6 \mathrm{~h}$ after the onset of ischemia and, then $20 \%$ of the total dose at the 12 th $\mathrm{h}$ and at the $18 \mathrm{th} \mathrm{h}$.

In permanent MCAO we followed the 2- and the 4-h protocol of the transient model, plus we applied the pretreatment $(0 \mathrm{~h})$ protocol: $50 \%$ of the total given dose was administered at ' 0 min' after the onset of ischemia, then $10 \%$ was given at the 6th, and $20 \%$ of the total dose at the 12 th and at the 18th hour. In the chronic permanent MCAO model we used exclusively the 0 min protocol.

Neurological scoring. Rats were tested for neurological deficit and scored as previously described by Meinzes and colleagues (8): 0 , no observable deficits; 1 , contralateral forelimb flexion when suspended; 2 , decreased grip of the contralateral forelimb while tail pulled; 3 , spontaneous movement in all directions and contralateral circling only if pulled by tail; 4 , spontaneous contralateral circling. Animals that had the features of the higher scores also showed all features of lower grades. The rater was naive to the treatment protocol and to the groups' identity. Assessments were made at 6 or at $24 \mathrm{~h}$ after the onset of ischemia. In the chronic permanent MCAO groups, the neurological scores were followed for 1 week.

Infarct size analysis. From removed and cooled brains (kept on ice) $1 \mathrm{~mm}$ coronal slices were obtained using an adult rat brain matrix. The sections were stained for $20 \mathrm{~min}$ at $37^{\circ} \mathrm{C}$ with $2 \%$ 2,3,5-triphenyl-tetrazolium chloride (TTC) solution. In a double-blinded manner infarction volume was calculated with the method described by Swanson and colleagues (9) to compensate for brain swelling in the ischemic hemisphere. Briefly, sections were scanned and the infarction area in each section was calculated by subtracting the non-infarct area of the ipsilateral side from the area of the contralateral side with $\mathrm{NIH}$ image analysis software. Infarction areas on each section were summed and multiplied by section thickness to give the infarction volume.

Histology and immunohistochemistry. Animals were perfused transcardially with ice-cold heparinized saline $(0.9 \%)$ followed by $4 \%$ paraformaldehyde in phosphate buffered saline (PBS) and post-fixed for 1 day in the same paraformaldehyde solution. The brain was removed and embedded in paraffin, and coronal sections $(5 \mu)$ were cut throughout the cerebral hemispheres. Sections at eight predetermined coronal levels (10) were stained for hematoxylin-eosin (H\&E) for assessment of ischemic damage to neuronal pericardia. Adjacent sections were processed for four types of immunochemical labeling as follows:
Immunohistochemical detection of APP (Alzheimer precursor protein) was conducted according to Valeriani and colleagues (11). Dewaxed sections were microwaved for $10 \mathrm{~min}$ in $10 \mathrm{mmol} / \mathrm{l}$ citric acid ( $\mathrm{pH} \mathrm{6.0)}$ ), allowed to cool, and incubated in $3 \% \mathrm{H}_{2} \mathrm{O}_{2}$ in methanol for $30 \mathrm{~min}$ and then for $1 \mathrm{~h}$ in $50 \mathrm{mmol} / 1 \mathrm{PBS}(\mathrm{pH} \mathrm{7.2)}$ containing $0.5 \%$ bovine serum albumin and $10 \%$ normal horse serum. After incubation overnight at $4^{\circ} \mathrm{C}$ with the monoclonal antibody against APP (diluted in 1/400 in PBS) the sections were incubated with the secondary antibody (biotinylated horse anti-mouse) followed by avidin-biotin complex (ABC kit). APP immunostaining was revealed with DAB as a chromagen, producing a brown stain. At the end of the procedure the sections were dehydrated, cleared and mounted.

Immunohistochemical detection of AIF (apoptosis-inducing factor): dewaxed sections were microwaved for $10 \mathrm{~min}$ in $10 \mathrm{mmol} / \mathrm{l}$ citric acid ( $\mathrm{pH} \mathrm{6.0)}$ ), allowed to cool, and incubated in $3 \% \mathrm{H}_{2} \mathrm{O}_{2}$ in methanol for $30 \mathrm{~min}$. Then non-specific binding was blocked by incubating the slides for $1 \mathrm{~h}$ in $0.25 \%$ Triton/ PBS containing $2 \%$ goat serum. After incubation with the polyclonal antibody against $\operatorname{AIF}(2.5 \mathrm{mg} / \mathrm{ml})$ the sections were incubated with the secondary antibody (biotinylated goat anti-rabbit) followed by avidin-biotin complex (ABC kit). AIF immunostaining was revealed with $\mathrm{Ni}$ enhanced-DAB as a chromogen, producing a black stain. Sections were then counterstained with nuclear fast red. At the end of the procedure the sections were dehydrated, cleared and mounted.

Immunohistochemical detection of poly(ADP-ribose): paraffin-embedded tissue sections were deparaffinized in xylene and rehydrated in decreasing concentrations (100, 95 and $70 \%$ ) of ethanol followed by a 5-min incubation in PBS. In order to prevent catabolism of the polymer by poly(ADPribose) glycohydrolase sections were fixed in $10 \%$ TCA (trichloroacetic acid). Then sections were treated with $0.3 \%$ hydrogen peroxide for 15 min to block endogenous peroxidase activity and then rinsed briefly in PBS. Non-specific binding was blocked by incubating the slides for $1 \mathrm{~h}$ in $0.25 \%$ Triton/ PBS containing $2 \%$ horse serum. To detect poly(ADP) ribose, a routine histochemical procedure was applied as previously described (12) with minor modifications as follows. Mouse monoclonal anti-poly(ADP-ribose) antibody and isotypematched control antibody was applied in a dilution of 1:300 for $1 \mathrm{~h}$ at room temperature. After extensive washing (3x10 min) with $0.25 \%$ Triton/PBS, immunoreactivity was detected with a biotinylated horse anti-mouse secondary antibody and the avidin-biotin-peroxidase complex (ABC) both supplied in the Vector Elite kit. Color was developed using Ni-DAB substratekit (Vector). Sections were then briefly rinsed in TRIS/Saline $(\mathrm{pH} 7.6)$ and incubated in Tris/Cobalt $(\mathrm{pH} 7.2)$ for $2 \mathrm{~min}$. Sections were then counterstained with nuclear fast red, dehydrated and mounted.

Immunohistochemical detection of NT (nitrotyrosine): nitrotyrosine labeling was performed similar to the previous protocol. The primary monoclonal anti-nitrotyrosine antibody (Upstate) was used in a concentration of $1 / 300$.

When photomicrographs were taken all histological and immunohistochemical samples were coded and examined and graded by an investigator in a blinded fashion. Histological and immunohistochemical staining was used exclusively for qualitative analysis. 
A.

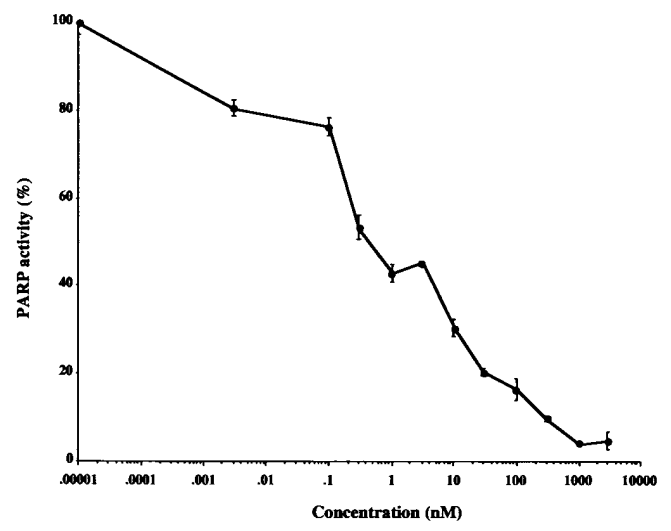

B.

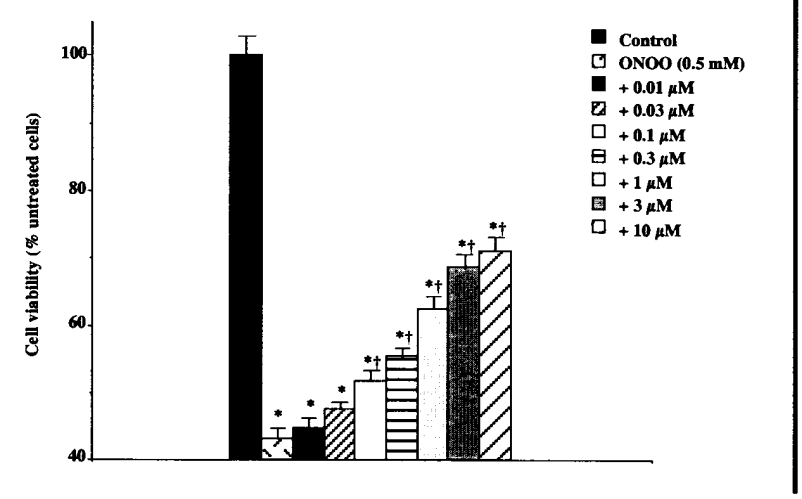

A.

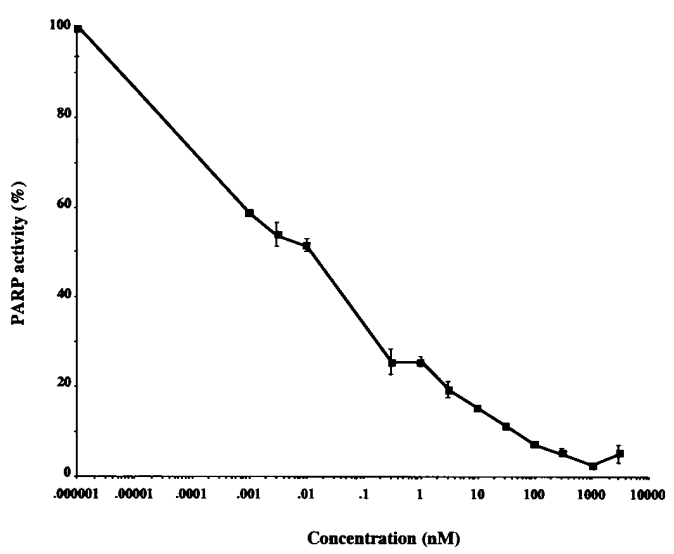

B.

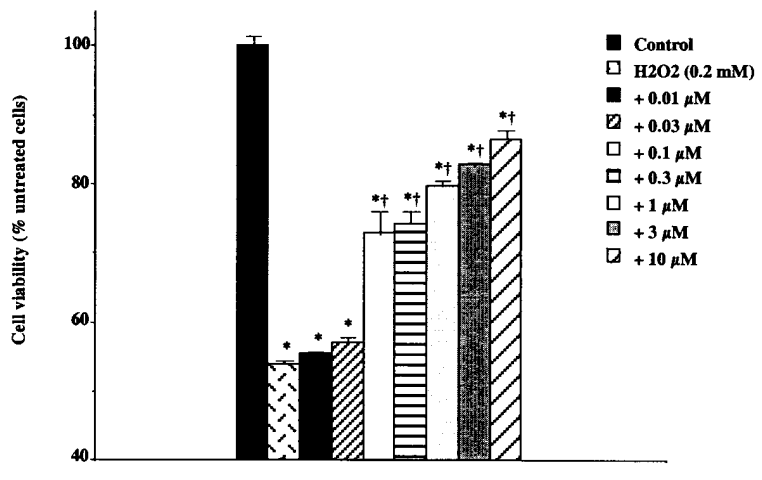

Figure 1. INO-1001 is a potent PARP inhibitor in cultured SK-N-MC cells. (Left), Effect of INO-1001 on peroxynitrite-mediated (A) activation of PARP and (B) decrease in cell viability. (Right), Effect of INO-1001 on hydrogen peroxide-mediated (A) activation of PARP and (B) decrease in cell viability. $\mathrm{n}=3$; ${ }^{*} \mathrm{p}<0.05 \mathrm{vs}$. untreated cells; ${ }^{\dagger} \mathrm{p}<0.05$ vs. hydrogen peroxide treated cells.

Statistical analysis. Results are reported as mean \pm SEM. For analysis of data one-way analysis of variance was applied and as a post hoc test Bonferroni multiple comparison test was used. The non-parametric behavior data was analyzed by medians, with Mann-Whitney U test. Survival curves were compared using log-rank test. Probability values of $p<0.05$ were considered significant.

Reagents. Reagents were obtained from Sigma/Aldrich (St. Louis, MO), unless indicated otherwise. Vehicle for INO-1001 (5\% Dextrose) was from Abbot Labs, Chicago, IL. Mouse monoclonal anti-poly (ADP-ribose) antibody was from Alexis (San Diego, CA). Mouse monoclonal anti-nitro tyrosine antibody was from Upstate (Lake Placid, NY). Rabbit polyclonal AIF (apoptosis-inducing factor) antibody was from Oncogene RP (Boston, MA). Mouse monoclonal APP (Alzheimer precursor protein) antibody was from Boehringer Mannheim CBP (Indianapolis, IN). Ni-DAB substrate kit, biotinylated horse, anti-mouse secondary antibody and avidin-biotinperoxidase kit and biotinylated goat, anti-rabbit secondary antibody and avidin-biotin-peroxidase kits were from Vector Laboratories (Burlingame, CA). Biotinylated goat, anti-rabbit secondary antibody and avidin-biotin-peroxidase kit (Vector Laboratories, Burlingame, CA).

\section{Results}

INO-1001 inhibits PARP and protects against oxidative and nitrosative stress-induced cell damage. INO-1001, PJ34 and 3-aminobenzamide all produced a dose-dependent inhibition of PARP activity in the isolated enzyme assays, with $\mathrm{IC}_{50}$ values of approximately $3 \mathrm{nM}, 30 \mathrm{nM}$ and $100 \mu \mathrm{M}$, respectively. By varying the concentration of the substrate, NAD in the PARP assay, the Ki of INO-1001 and PJ34 were determined as being approximately 15 and $200 \mathrm{nM}$, respectively. All PARP inhibitors dose-dependently protected against oxidant-induced cytotoxicity in the thymocyte assay, with EC50 values of approximately $10 \mathrm{nM}, 100 \mathrm{nM}$ and $20 \mu \mathrm{M}$. The potency of INO-1001 as a PARP inhibitor and its cytoprotective potential were subsequently confirmed in the human neuronal line SKN-MC. Peroxynitrite induced a marked activation of PARP in these cells, an effect which was dose-dependently inhibited by INO-1001 (Fig. 1). Incubation of SK-N-MC cells with peroxynitrite for $2 \mathrm{~h}$ reduced cell viability by $57 \%$, an effect, which was dose-dependently, but not fully reversed by INO-1001. Similarly, INO-1001 dose-dependently protected against hydrogen peroxide-induced PARP activation, and restored the viability of hydrogen peroxide treated cells (Fig. 1). The concentration for half-maximal inhibition of PARP and 
A

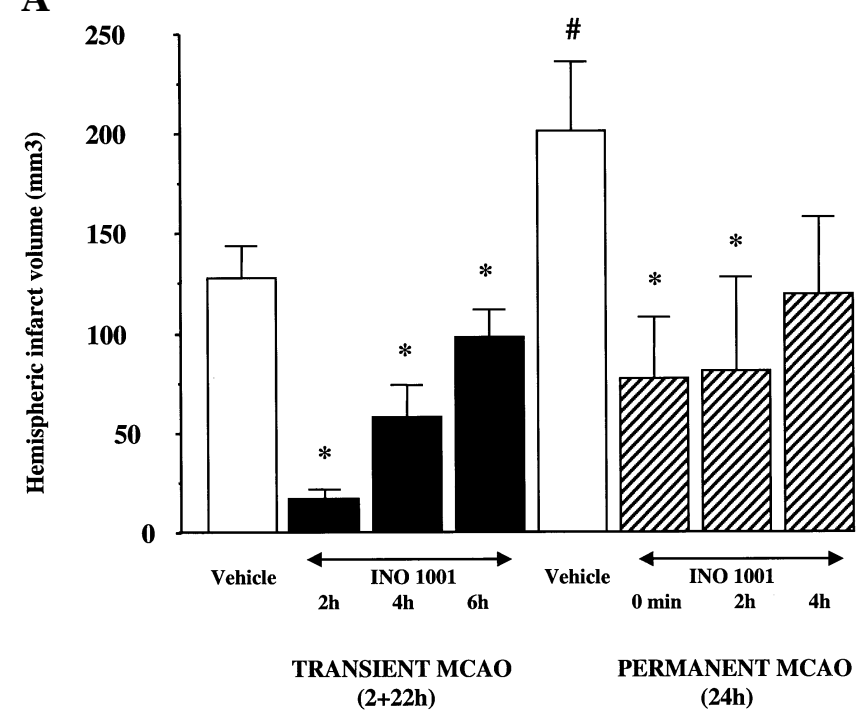

B

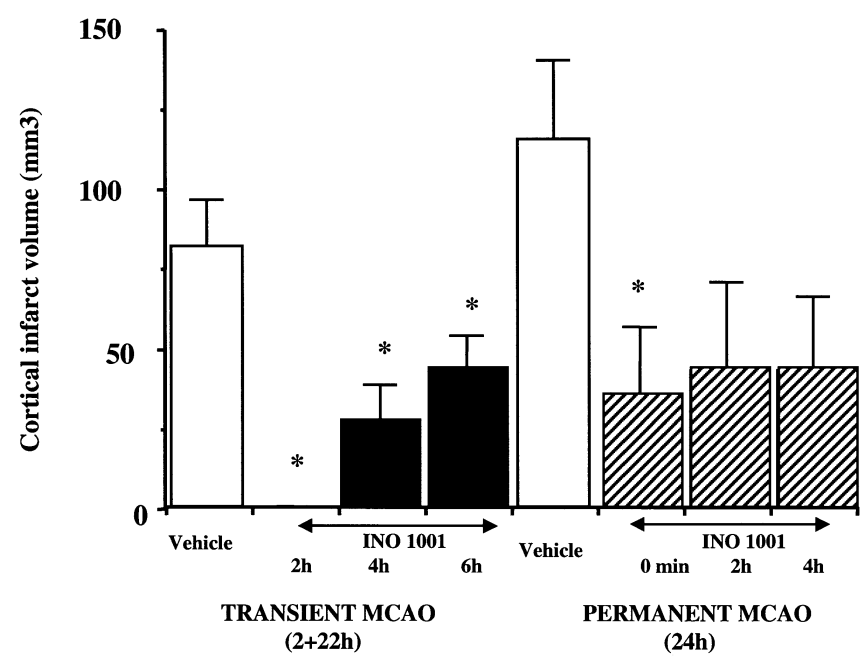

Figure 2. INO-1001 reduces infarct size in transient and permanent MCAO: total (A) and cortical (B) infarct volumes. The number of animals in the transient groups: vehicle $\mathrm{n}=8$; INO-1001/2 $\mathrm{h} \mathrm{n}=7$; INO-1001/4 $\mathrm{h} \mathrm{n}=6$; INO$1001 / 6 \mathrm{~h} n=8$. In all the permanent MCAO groups $\mathrm{n}=6$. ${ }^{*} \mathrm{p}<0.05$ compared to vehicle treated respective controls. ${ }^{\#} \mathrm{p}<0.05$ compared to the vehicle treated transient MCAO.

restoration of cell viability ranged between 0.1 and $1 \mathrm{nM}$ for PARP inhibition and was approximately $300 \mathrm{nM}$ for restoration of cellular viability.

INO-1001 reduces infarct size in stroke with a long therapeutic window. The PARP inhibitor INO-1001 significantly reduced infarct size following both transient and permanent focal cerebral ischemia in rats. INO-1001 $(3 \mathrm{mg} / \mathrm{kg} / 24 \mathrm{~h})$ provided a $86 \%$ reduction in total hemispheric infarct size, when its administration began $2 \mathrm{~h}$ after occlusion in transient MCAO, and remained effective in the 4- and 6-h post-treatment regimen (Fig. 2).

In the permanent MCAO model, INO-1001produced a $62 \%$ reduction in total infarct size of the permanent MCAO model when drug administration followed immediately after the onset of the permanent occlusion (Fig. 2), and remained effective in the 2 -h post-treatment regimen.
Transient MCAO $(2+22 h)$

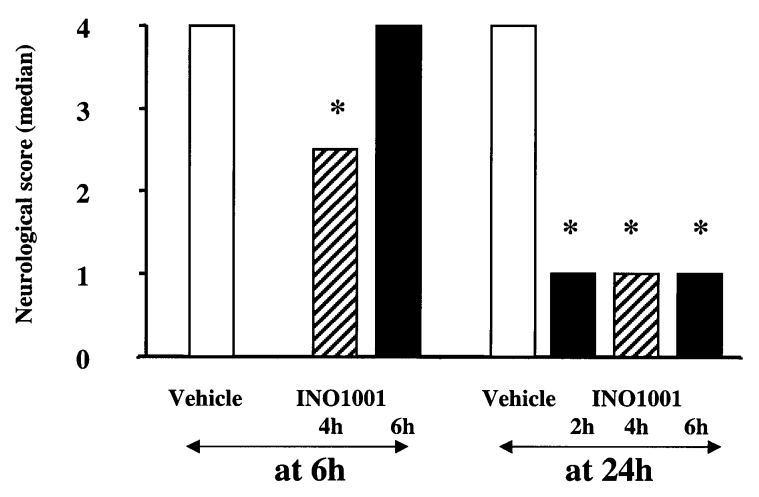

Permanent MCAO (24h)

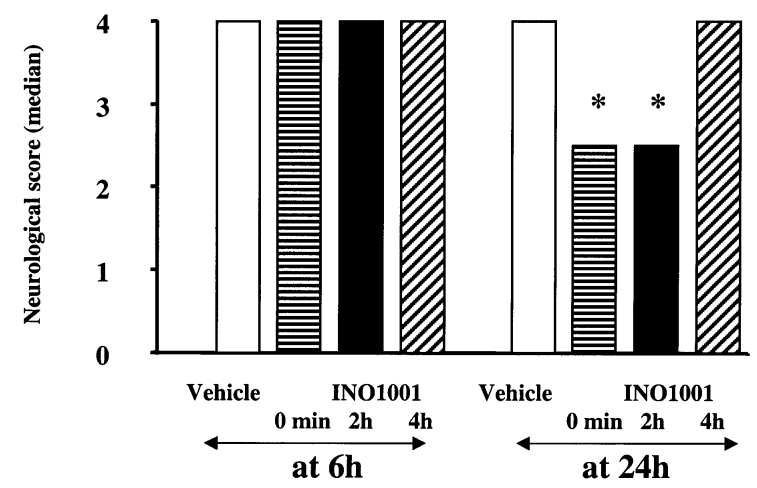

Figure 3. PARP inhibition improves neurological function in stroke, as determined individually after the 6th and the 24th hour of ischemic insult. ${ }^{*} \mathrm{p}<0.05$ significant protective effect of the PARP inhibitor.

PARP inhibition improves neurological status. Marked improvements in the neurological status were observed after PARP inhibition with INO-1001 in either transient or permanent MCA occluded rats (Fig. 3). In the $6 \mathrm{~h}$ INO-1001 post-treatment group (transient MCAO), neurological scores were high (median score $=4$ ) at $6 \mathrm{~h}$ in all groups, but in the PARP inhibitor treated animals they showed a marked improvement (median scores $=1 \mathrm{~h}$ ) by $24 \mathrm{~h}$, whereas they remained the same (median score $=4$ at $24 \mathrm{~h}$ ) in the vehicle treated animals.

Improvement of the neurological score was also observed when the start of the PARP inhibitor administration was 2-h post-occlusion in the permanent occlusion protocol (Fig. 3).

In the 1-week follow-up studies in rats with permanent MCAO the protective effect of PARP inhibition was maintained until the end of the observation period. For instance, median neurological scores decreased from 3 (at $24 \mathrm{~h})$ to $2(96 \mathrm{~h})$ and $1.5(168 \mathrm{~h})$. All permanently occluded animals died by the 72 nd hour in vehicle treated group, while during INO-1001 administration from 5 animals only 1 died, which occurred at the end of the 7 th day.

PARP inhibition reduces poly(ADP-ribose) formation and APP accumulation. Histological evidence of ischemic brain damage in the gray matter of the cerebral cortex and caudate nucleus was observed in all animals subjected to either transient (Fig. 4) or permanent MCA occlusion. Neurons 


\section{Sham operated control striatum}
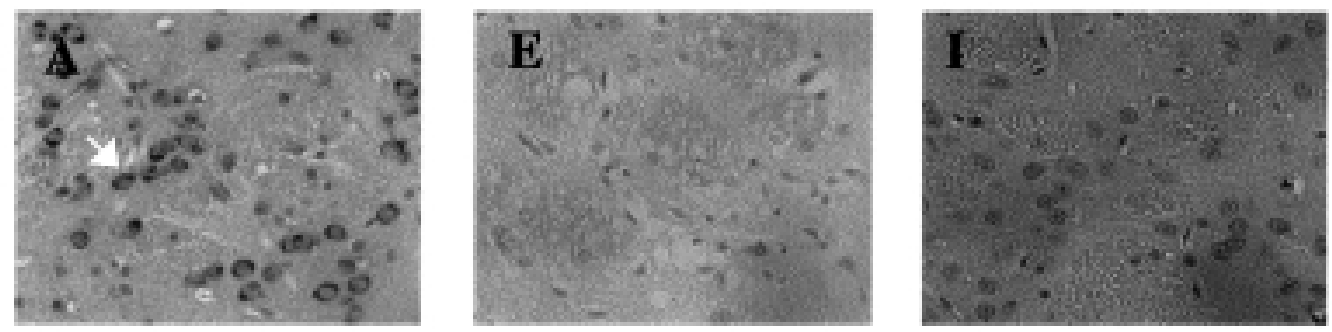

1h MCAO
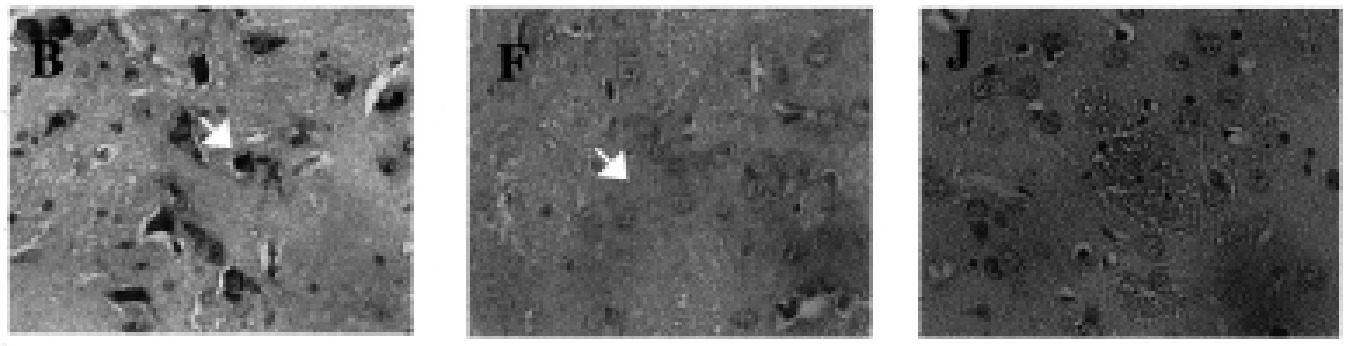

2h MCAO + 1h Reperfusion
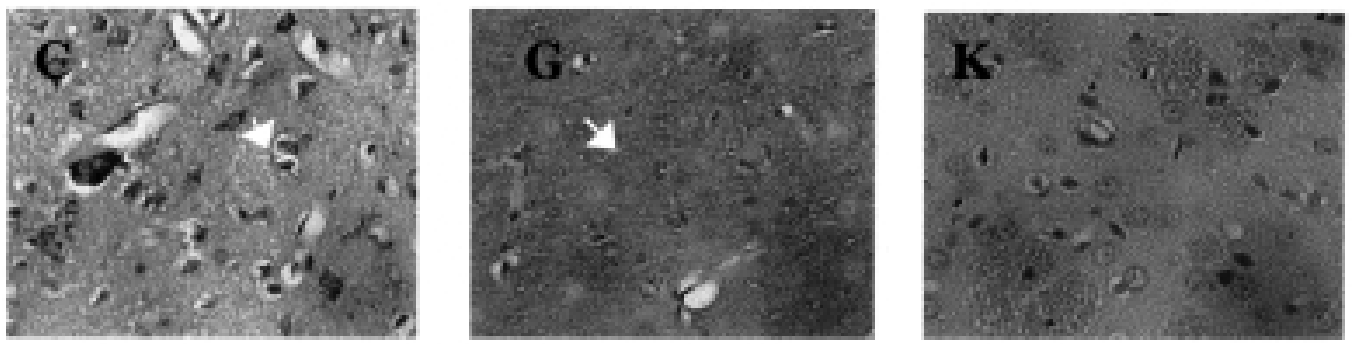

2h MCAO + 22h Reperfusion

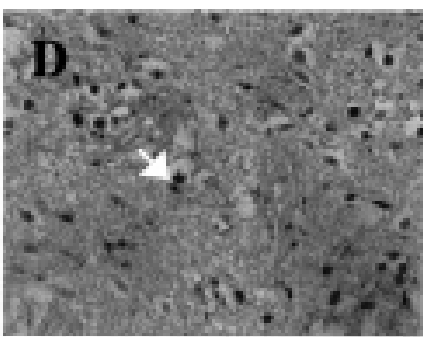

PAR

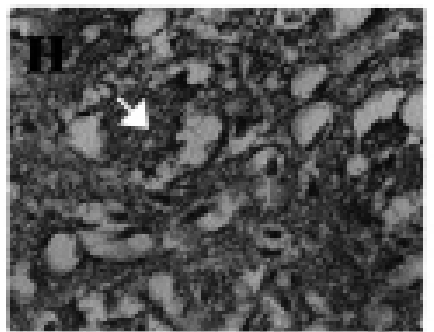

NT

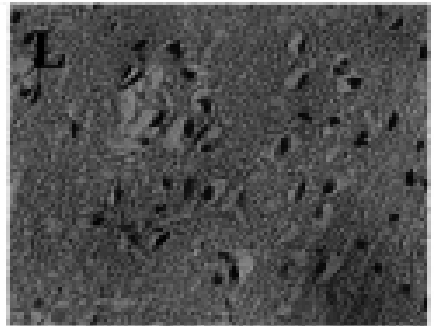

H\&E

Figure 4. Time-course of poly(ADP-ribose) formation in stroke. Time course of histological (I-L), PAR immunohistochemical (A-D) and nitrotyrosine immunohistochemical $(\mathrm{E}-\mathrm{H})$ changes in focal cerebral MCAO. Arrows indicate the nuclear localization of PAR or the diffuse cytoplasmic localization of nitrotyrosine.

within the area of neocortex and caudate nucleus supplied by MCA had a characteristic pyknotic appearance of ischemic damage (Fig. 4L).

After stroke, we detected high levels of nuclear ADPribose formation in the ipsilateral hemisphere starting at $1 \mathrm{~h}$ of MCA occlusion (Fig. 4B). PARP inhibition by INO-1001 attenuated the accumulation of poly(ADP-ribose) in the ischemic/reperfused hemisphere (Fig. 5A).

The changes in APP immunostaining described below were observed only within the boundaries of the lesions, as defined histologically in gray matter. In the non-ischemic hemisphere APP immunoreactivity was faint. In contrast, in the ipsilateral hemisphere anatomically circumscribed zones of increased APP immunoreactivity were observed in the external and internal capsule, in the myelinated fiber tracts permeating the striatum, in the anterior comissure, and in the medial forebrain bundle (Fig. 5B). The increased axonal immunoreactivity was 'bulbous' in appearance, reminiscent of axonal swellings which occur following traumatic brain injury and which is an early indicator of axotomy $(13,14)$. INO-1001 administration reduced the accumulation of APP in the white matter of the affected hemisphere (Fig. 5B). 
A
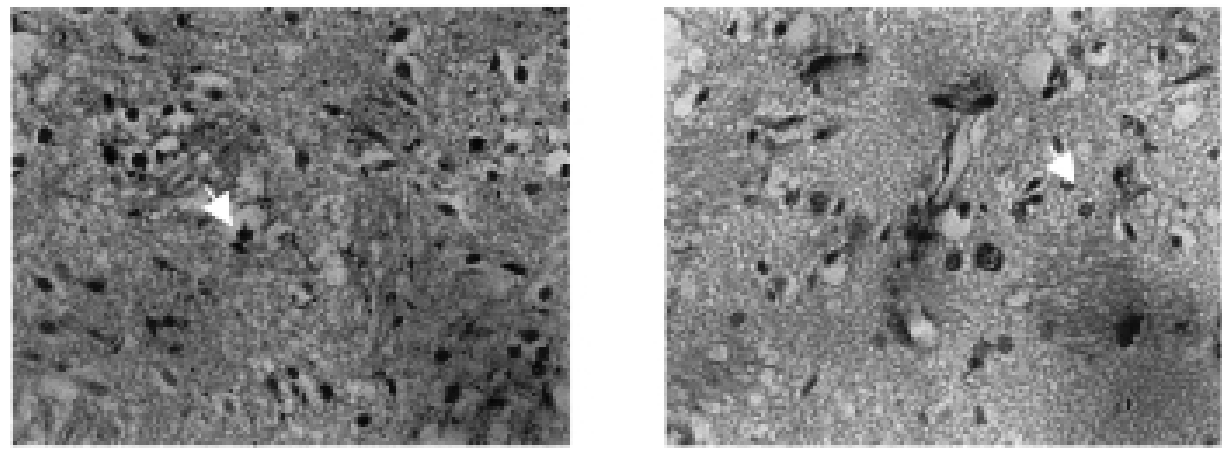

\section{STRIATUM}

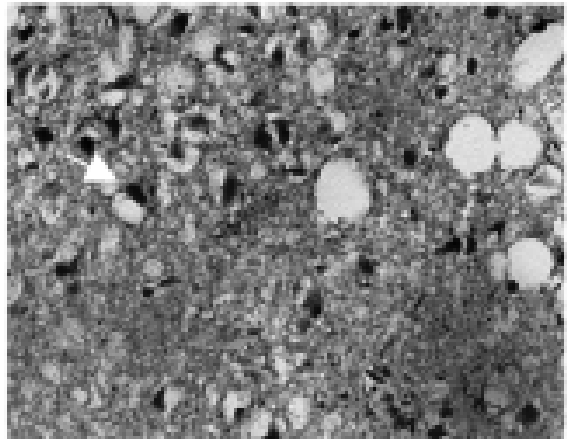

STROKE

B
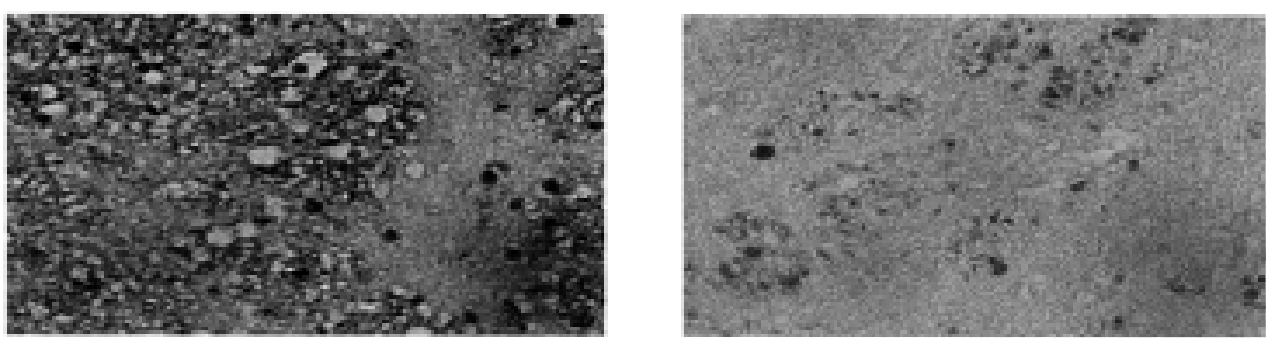

Striatum
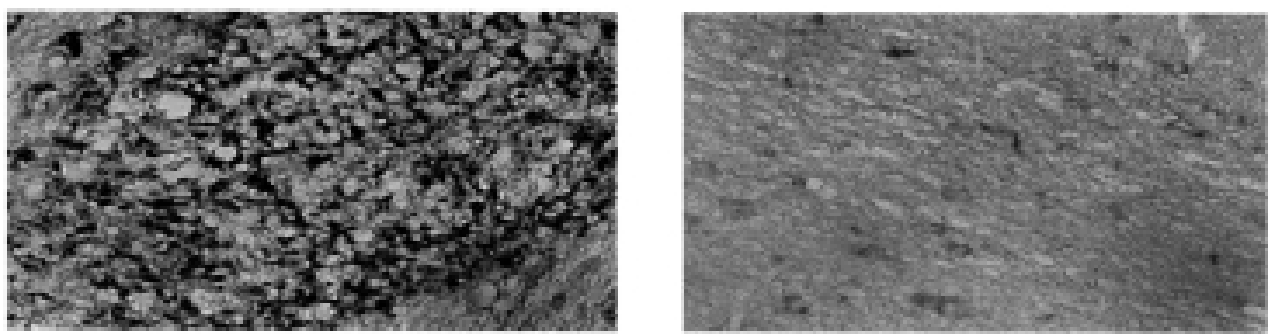

\section{Internal} capsule

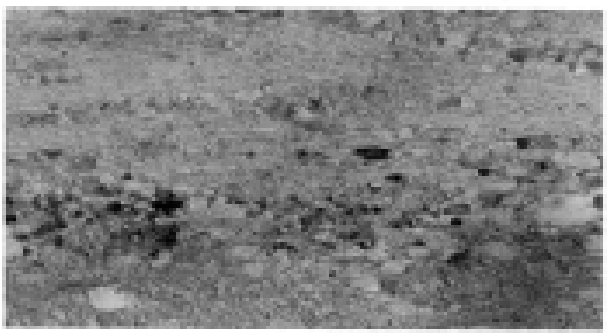

STROKE

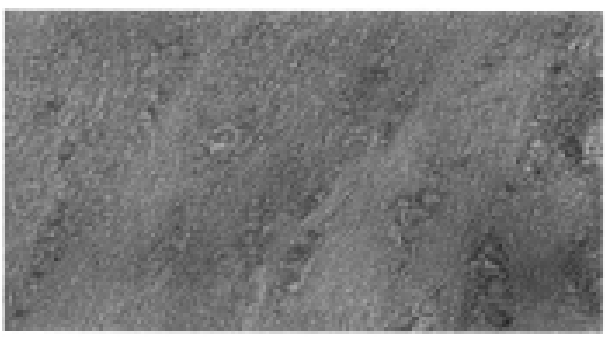

External capsule

\section{STROKE+INO1001}

Figure 5. INO-1001 inhibits poly(ADP-ribose) formation (A) and protects against white matter damage (B) in stroke. Effect of INO-1001 treatment in various anatomical regions of the transient MCA occluded rats (2-h occlusion/22-h reperfusion). Arrows indicate the presence (stroke) and attenuation (stroke + INO1001) of nuclear PAR staining and axonal APP labeling. 


\section{STRIATUM}
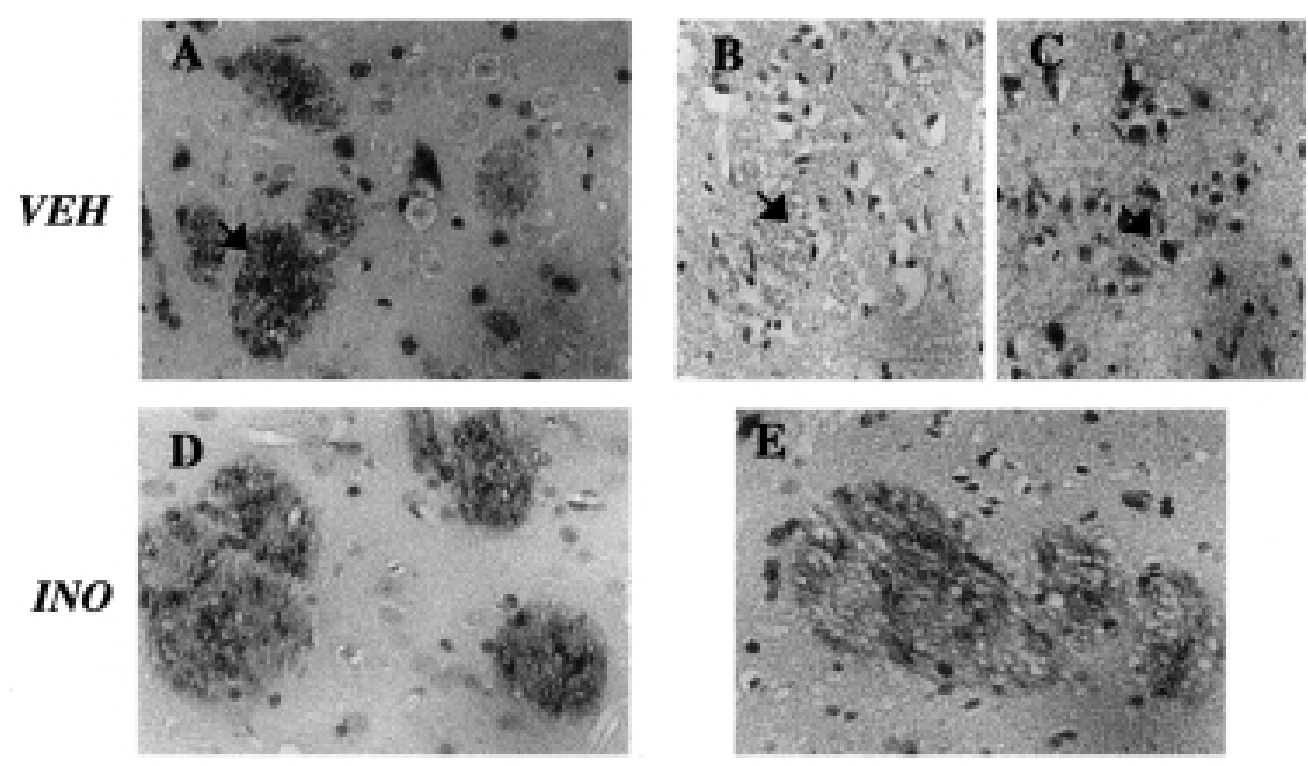

\section{EXTERNAL CAPSULE}
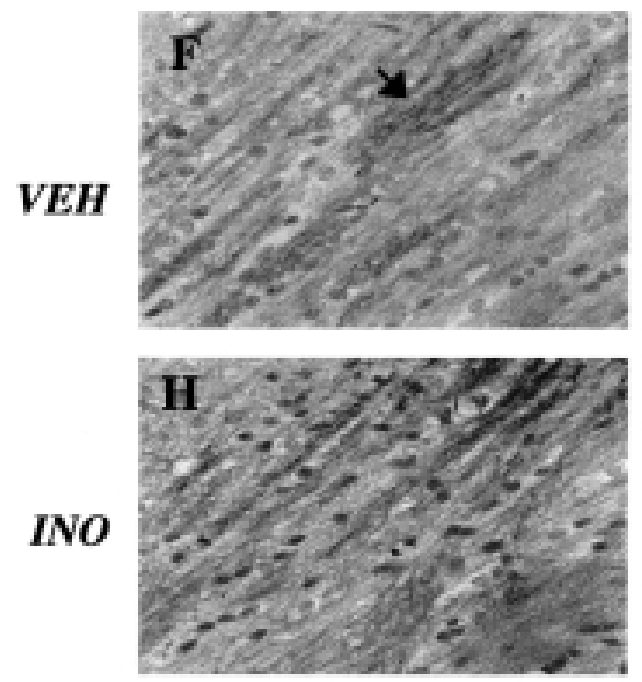

CONTRALATERAL
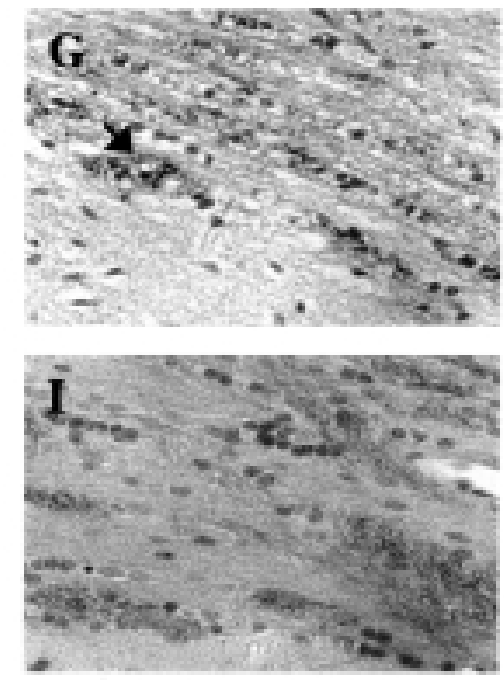

IPSILATERAL MCAO

Figure 6. AIF translocation is dependent on PARP activation in stroke. Effect of INO-1001 treatment in two anatomical regions (striatum, external capsule) of the transient MCA occluded rats (2-h occlusion/22-h reperfusion). Arrows represents the presence (A and D-I), the absence (B) and the nuclear translocation (C) of AIF (VEH, vehicle; INO, INO-1001).

We also visualized nitrotyrosine, a marker of nitrosative stress $(15,16)$. A cytoplasmatic staining was seen (Fig. 3). Slight reduction in nitrotyrosine staining was observed in the INO-1001 treated rats (data not shown).

AIF translocates in stroke, which is regulated by PARP activity. The normal, cytoplasmatic localisation of AIF was detected in the normal contralateral brain tissues, delineating mainly the axonal territories (Fig. 6A and F). AIF labeling developed in neuronal nuclei of the border zone icheamic area of the striatum after stroke (Fig. 6C). Cytoplasmatic AIF staining diminished in the necrotic core of the striatum (Fig. 6B), while it was enhanced at the borderline ischemic territories of the white matter (Fig. 6G). Inhibition of PARP with INO1001 reshifted the location of the apoptotic marker to the axons in the ipsilateral striatum (Fig. 6E) and the normal axonal appearance of AIF reappeared in the borderline white matter territories, such as the external capsule (Fig. 6I).

\section{Discussion}

PARP activation drives cell necrosis via suppression of cellular energetic pools and impairment of mitochondrial function (17-19), overviewed in ref. 1 . This pathway contributes to the pathogenesis of NMDA-mediated neuronal injury in stroke: PARP inhibitors protect against NMDA-mediated neurotoxicity 
in vitro $(20,21)$ and in vivo (22). PARP deficient mice are markedly resistant against stroke $(21,23)$. Pharmacological inhibitors of PARP also provide neuroprotection (24-30), but the degree of protection tends to be less pronounced than the protection seen in PARP-1 deficient animals. Many PARP inhibitors appear to have a limited CNS uptake and cellular residence time (31).

We found that the PARP inhibitor INO-1001 provided marked beneficial effects in both transient and permanent models of rat MCA occlusion. The compound reduced poly(ADP-ribose) generation in the brain, demonstrating its uptake into the CNS. The therapeutic window of opportunity was approximately $6 \mathrm{~h}$ in the transient model, which is similar the therapeutic window of nicotinamide, a PARP inhibitor of low potency. Nicotinamide has many additional actions, such as antioxidant effects and replenishment of cellular pyridine nucleotide pools (32), which makes direct comparisons difficult. The dose of nicotinamide was over 100 times higher than the dose of the PARP inhibitor used in the current study.

We found that not only the stroke volume but also the accumulation of APP, a marker of axonal damage (33) was diminished by PARP inhibition. This protective effect is in contrast to several other neuroprotective approaches, most notably NMDA receptor blockers (34).

PARP inhibition or PARP deficiency improves mitochondrial function in oxidant-challenged cells (18). In vitro the oxidant-mediated translocation of the mitochondrial protein AIF into the nucleus is dependent on PARP activation (2), demonstrating that AIF translocation occurs in stroke in vivo, and proves that this process can be suppressed by pharmacological inhibition of PARP. The reduced nitrosative stress in the brain sections of PARP inhibitor-treated animals may also be a consequence of an improved mitochondrial function: we have previously reported that the secondary oxidant generation in oxidant-challenged cells is diminished in the presence of PARP inhibitors or in PARP-1 deficient cells (18).

The results of the current study are consistent with the notion that potent PARP inhibitors may be candidates for development as neuroprotective agents. We also demonstrated that there is an ischemic mitochondrial-to-nuclear translocation of AIF, and PARP is involved in this process. Inhibition of AIF-mediated pathophysiological processes may be an additional mode of protection of PARP inhibitors in stroke.

\section{Acknowledgements}

This study was supported by grants from the National Institutes of Health R44 NS37635 and R44 NS37985.

\section{References}

1. Virag L and Szabo C: The therapeutic potential of PARP inhibitors. Pharmacol Rev 54: 375-429, 2002.

2. Yu SW, Wang H, Poitras MF, Coombs C, Bowers WJ, Federoff HJ, Poirier GG, Dawson TM and Dawson VL: Mediation of PARP-1-dependent cell death by apoptosisinducing factor. Science 297: 259-263, 2002.

3. Shimoda K, Murakami K, Enkhbaatar P, Traber LD, Cox RA, Hawkins HK, Schmalstieg FC, Komjati K, Mabley JG, Szabo C, Salzman AL and Traber DL: Effect of poly(ADP ribose) synthetase inhibition on burn and smoke inhalation injury in sheep. Am J Physiol Lung Cell Mol Physiol 285: L240-L249, 2003.
4. Khan TA, Ruel M, Bianchi C, Voisine P, Li J, Baker J, Komjáti K, Szabó C and Sellke FW: Poly-ADP-ribose synthetase inhibition improves postischemic myocardial function after cardiopulmonary bypass. J Am Coll Surg 197: 270-277, 2003.

5. Jagtap P, Soriano FG, Virag L, Liaudet L, Mabley J, Szabo E, Hasko G, Marton A, Lorigados CB, Gallyas F Jr, Sumegi B, Hoyt DG, Baloglu E, van Duzer J, Salzman AL, Southan GJ and Szabo C: Novel phenanthridinone inhibitors of poly (adenosine 5'-diphosphate-ribose) synthetase: potent cytoprotective and anti-shock agents. Crit Care Med 30: 1071-1082, 2002.

6. Garcia Soriano F, Virag L, Jagtap P, Szabo E, Mabley JG, Liaudet L, Marton A, Hoyt DG, Murthy KG, Salzman AL, Southan GJ and Szabo C: Diabetic endothelial dysfunction: the role of poly(ADP-ribose) polymerase activation. Nat Med 7: 108-113, 2001.

7. Longa ZE, Weinstein PR, Carlson S and Cummins R: Reversible middle cerebral artery occlusion without craniectomy in rats. Stroke 20: 84-91, 1989

8. Meinzes SA, Hoff JT and Betz AL: Middle cerebral artery occlusion in rats: a neurological and pathological evaluation of a reproducible model. Neurosurgery 31: 100-107, 1999.

9. Swanson RA, Morton MT, Tsao-Wu G, Savalos RA, Davidson C and Sharp FR: A semiautomated method for measuring brain infarct volume. J Cereb Blood Flow Metab 10: 290-293, 1990.

10. Osborne KA, Shigeno T, Balarsky AM, Ford I, McCulloch J, Teasdale GM and Graham DI: Quantitative assessment of early brain damage in a rat model of focal cerebral ischemia. J Neurol Neurosurg Psychiatry 50: 402-410, 1987.

11. Valeriani V, Dewar V and McCulloch J: Quantitative assessment of ischemic pathology in axons, oligodendrocytes and neurons: attenuation of damage after transient ischemia. J Cereb Blood Flow Metab 20: 765-771, 2000.

12. Liaudet L, Soriano FG, Szabo E, Virag L, Mabley JG, Salzman AL and Szabo C: Protection against hemorrhagic shock in mice genetically deficient in poly(ADP-ribose) polymerase. Proc Natl Acad Sci USA 97: 10203-10208, 2000.

13. McCulloch J, Komjati K, Valeriani V and Dewar D: Beyond neuroprotection of axons and oligodendrocytes in cerebral ischaemia. In: Cerebrovascular Diseases, 22nd Princeton Conference. Pak H (ed). Chan, Cambridge University Press, pp404-415, 2002.

14. Povlishock JT, Becker DP, Cheng CL and Vaughan GW: Axonal changes in minor head injury. $J$ Neuropathol Neurobiol 42: 225-242, 1983.

15. Beckman JS and Koppenol WH: Nitric oxide, superoxide, and peroxynitrite: the good, the bad, and ugly. Am J Physiol 271: C1424-C1437, 1996.

16. Greenacre SA and Ischiropoulos H: Tyrosine nitration: localisation, quantification, consequences for protein function and signal transduction. Free Radic Res 34: 541-581, 2001.

17. Heller B, Wang ZQ, Wagner EF, Radons J, Burkle A, Fehsel K, Burkart $\mathrm{V}$ and Kolb $\mathrm{H}$ : Inactivation of the poly(ADP-ribose) polymerase gene affects oxygen radical and nitric oxide toxicity in islet cells. J Biol Chem 270: 11176-11180, 1995.

18. Virag L, Salzman AL and Szabo C: Poly(ADP-ribose) synthetase activation mediates mitochondrial injury during oxidant-induced cell death. J Immunol 161: 3753-3759, 1998.

19. $\mathrm{Ha} \mathrm{HC}$ and Snyder SH: Poly(ADP-ribose) polymerase is a mediator of necrotic cell death by ATP depletion. Proc Natl Acad Sci USA 96: 13978-13982, 1999.

20. Zhang J, Dawson VL, Dawson TM and Snyder SH: Nitric oxide activation of poly(ADP-ribose) synthetase in neurotoxicity. Science 263: 687-689, 1994.

21. Eliasson MJ, Sampei K, Mandir AS, Hurn PD, Traystman RJ, Bao J, Pieper A, Wang ZQ, Dawson TM, Snyder SH and Dawson VL: Poly(ADP-ribose) polymerase gene disruption renders mice resistant to cerebral ischemia. Nat Med 3: 1089-1095, 1997.

22. Mandir AS, Poitras MF, Berliner AR, Herring WJ, Guastella DB, Feldman A, Poirier GG, Wang ZQ, Dawson TM and Dawson VL: NMDA but not non-NMDA excitotoxicity is mediated by poly(ADP-ribose) polymerase. J Neurosci 20: 8005-8011, 2000.

23. Endres M, Wang ZQ, Namura S, Waeber C and Moskowitz MA: Ischemic brain injury is mediated by the activation of poly(ADPribose) polymerase. J Cereb Blood Flow Metab 17: 1143-1151, 1997. 
24. Endres M, Scott G, Namura S, Salzman AL, Huang PL, Moskowitz MA and Szabo C: Role of peroxynitrite and neuronal nitric oxide synthase in the activation of poly(ADP-ribose) synthetase in a murine model of cerebral ischemia-reperfusion. Neurosci Lett 248: 41-44, 1998.

25. Takahashi K, Pieper AA, Croul SE, Zhang J, Snyder SH and Greenberg JH: Post-treatment with an inhibitor of poly(ADPribose) polymerase attenuates cerebral damage in focal ischemia. Brain Res 829: 46-54, 1999.

26. Endres M, Scott GS, Salzman AL, Kun E, Moskowitz MA and Szabo C: Protective effects of 5-iodo-6-amino-1,2-benzopyrone, an inhibitor of poly(ADP-ribose) synthetase against peroxynitriteinduced glial damage and stroke development. Eur J Pharmacol 351: 377-382, 1998 .

27. Abdelkarim GE, Gertz K, Harms C, Katchanov J, Dirnagl U, Szabo C and Endres M: Protective effects of PJ34, a novel, potent inhibitor of poly(ADP-ribose) polymerase (PARP) in in vitro and in vivo models of stroke. Int J Mol Med 7: 255-260, 2001.

28. Ding Y, Zhou Y, Lai Q, Li J, Gordon V and Diaz FG: Longterm neuroprotective effect of inhibiting poly(ADP-ribose) polymerase in rats with middle cerebral artery occlusion using a behavioral assessment. Brain Res 915: 210-217, 2001.
29. Goto S, Xue R, Sugo N, Sawada M, Blizzard KK, Poitras MF, Johns DC, Dawson TM, Dawson VL, Crain BJ, Traystman RJ, Mori S and Hurn PD: Poly(ADP-ribose) polymerase impairs early and long-term experimental stroke recovery. Stroke 33: 1101-1106, 2002.

30. Ayoub IA and Maynard KI: Therapeutic window for nicotinamide following transient focal cerebral ischemia. Neuroreport 13: 213-216, 2002.

31. Southan GJ and Szabo C: Poly(ADP-ribose) polymerase inhibitors. Curr Med Chem 10: 321-340, 2003.

32. Szabo C: Nicotinamide: a jack of all trades (but master of none?). Intensive Care Med 29: 863-866, 2003.

33. Stephenson DT, Rash K and Clemens JA: Amyloid precursor protein accumulates in regions of neurodegeneration following focal cerebral ischaemia in rat. Brain Res 393: 128-135, 1992.

34. Yam PS, Dunn LT, Graham DI, Dewar D and McCulloch J: NMDA receptor blockade fails to alter axonal injury in focal cerebral ischemia. J Cereb Blood Flow Metab 20: 772-779, 2000 . 